\title{
TESTIMONIOS DIPLOMÁTICOS EN LA CRÓNICA DE JAIME I
}

\author{
M. ${ }^{\text {a }}$ Desamparados Cabanes Pecourt \\ Universidad de Zaragoza
}

Cualquier texto de cualquier época acostumbra a recoger entre sus líneas, voluntaria o involuntariamente, retazos de la vida coetánea. Costumbres, alimentación, vestidos, ritos, celebraciones, etc., los vemos reflejados en todos ellos en mayor o menor proporción según el carácter de la obra escrita.

Ya en otra ocasión hicimos el paralelismo entre una serie de testimonios o ejemplares diplomáticos que aparecian en la obra literaria de Joanot Martorell, Tirant lo Blanch, auténtica novela de caballerias del siglo XV valenciano, con los vigentes para la misma época en la sociedad valenciana (1). Ahora hemos revisado la Crónica de Jaime I, conocida como Libre dels Feyts, en donde vemos aparecer frecuentemente toda una serie de alusiones al documento escrito o a su mundo, entremezcladas con el devenir de los acontecimientos. Notarios, escribanos, sellos y otras clases de menciones diplomáticas, si bien que de forma somera, asoman a lo largo del texto cronístico, y a todo ello vamos a referirnos.

En las alusiones al elemento humano, se distinguen dos categorías: la del escribano y la del notario. El primero reduce su actividad siempre a la propia de su oficio, la de escribir. $Y$ así, aunque indirectamente puede hallarse aludido en las repetidas menciones de confección de las cartas, lo es de forma directa en unas pocas ocasiones. Una de ellas se sitúa en 1233, al tratarse la capitulación de Peñíscola ofrecida por los propios musulmanes, que 
no puede confirmarse por escrito ante la ausencia de los escribanos reales a los que se espera en fecha próxima. Para remediar esta situación, Jaime I marcha a Tortosa al día siguiente de esta entrevista y vuelve seguidamente a Peñíscola con ellos, ordenándoles extender las correspondientes escrituras (2).

Transcurrido un cierto tiempo, se mencionará nuevamente en el texto el nombramiento de un escribano en Montpellier, destinado a recibir las declaraciones de los testigos y a averiguar las circunstancias relativas al pleito que se había suscitado entre el conde de Ampurias y Ponce Guillem de Torrella, premisas previas a la sentencia que deberá dictar el monarca (3).

Asimismo, en 1258, y con motivo de un asunto de falsificación de mone$\mathrm{da}$, al aparecer un testigo que se presta a colaborar, el rey tiene dispuesto un escribano que deje constancia escrita de su declaración (4).

Cualidad sobresaliente de alguno de estos profesionales en el ejercicio de su función es el conocimiento idiomático en un mundo políglota. Tal es el caso de en Astruch, juheu, qui era scriva nostre d'algaravia (5), o del alfaquí real Salomón (6); si bien existían algunos otros casos aún cuando no conozcamos a sus protagonistas, pues son repetidas las menciones de textos redactados en esta lengua a lo largo de la crónica real, unas veces por parte de esta cancillería (7), otros procedentes de los propios musulmanes (8), como en la rendición de Peñíscola, aunque, como claramente se comprende, este último ejemplo es obvio.

Excepcionalmente - pues no se trata de una acción profesional- aun podemos constatar una cita más referida a un escribano en que éste no se caracteriza por su buen hacer sino por todo lo contrario, lo que determina al monarca a pedir su expulsión del lugar de Zuera, en donde los hombres de Pedro Cornel -éste entre ellos- habían causado diferentes daños (9).

En el caso de los notarios, su mayor importancia social y representativa hace que sean nombrados en la Crónica, no por su actuación profesional, sino por su papel como representantes reales, actuando unas veces de embajadores del monarca, o asistiendo a reuniones en que el rey les pide parecer, aunquie en este último caso pueden aparecer nominados entre los consejeros reales sin distinción de su cargo.

Es de destacar la mención de Jaime Çarroca, sacristán de Lérida y notario real, que marcha ante el rey de Castilla como representante del monarca aragonés (10). 
Dejando, pues, el factor humano y entrando ya en el terreno estrictamente diplomático -el de los escritos o documentos-, la nomenclatura empleada por Jaime I en su Crónica es totalmente sencilla. A todo testimonio escrito se le denomina carta, bien la emanada desde la cancilleria real, bien la recibida por el monarca procedente de los más diversos orígenes, independientemente de su contenido jurídico.

En muchas ocasiones parece ser que estas cartas mantienen solamente un carácter epistolar, siendo vehículo de comunicación o mero portador de noticias desde otros emisarios al rey, aunque no estén exentas de carga polftica. Ese es el caso de las que el rey recibe de su hija en petición de ayuda (11); la que el propio rey envía a los habitantes de Elche demandando entrevistarse (12), o al alcaide de Játiva reclamándolo a su presencia (13); la que él mismo recibe del rey de los Tártaros, de carácter amigable (14); la de la reina, comunicándole la toma del castillo de Penáguila por parte de Alazrach (15); o la que le hace llegar el papa Gregorio X referente al tema de Tierra Santa (16). En otras, la actuación política queda patente, como en las enviadas por los musulmanes con oferta de rendición de sus diversas plazas, que luego llevarán aparejadas la expedición de otros documentos como respuesta real, en que se contendrán las condiciones de la anexión. Así vemos las de Almenara (17), Paterna (18), etc.

Tan sólo en uno de todos de estos casos, la carta -entendida genéricamente-- recibe además otra denominación, única asimismo en el texto, y es al recibir Jaime I carta de su hija, la reina de Castilla, en demanda de ayuda, en que éste, al tener que dar su respuesta, hace alusión a aquella -a la que luego denominará cara carta - diciendo haguem vistes les letres (19); dando así el nombre de letra al documento escrito, terminología, por otra parte, común en la época medieval.

Cuestión aparte es la que se refiere a la emisión de los diferentes documentos por parte de la cancillería del rey conquistador, variados a lo largo de su Crónica aunque polarizados en torno a los asuntos que en la misma se narran.

Por lo que respecta a la denominación genérica concedida al objeto diplomático, ya deciamos antes que recibe únicamente la de carta, referida siempre al momento de su génesis. Documentos diversos, relativos a donaciones, treguas, rendiciones, cartas de creencia, confirmación de privilegios, etc., son expresados respecto a su redacción con la frase fer carta/cartes (20). 
No obstante y a pesar de la sobriedad de los datos aportados sobre el tema, podemos rastrear algunos tipos documentales por las adiciones que sobre su tenor añade el texto (aunque muchos más de los aquí señalados podríamos deducirlos por el contexto), entre los cuales entresacaremos los siguientes:

\section{CARTA DE DONACIÓN}

Una de las más interesantes es la que Jaime I concediera al noble aragonés, Blasco de Alagón, en 1226, otorgándole todas las villas y castillos que consiguiera ganar a los musulmanes (21), verdadero cheque en blanco del que más tarde se arrepentiria el monarca, pero que fue la causa próxima que le espoleó a decidirse por la conquista del Reino de Valencia después de que Blasco de Alagón conquistara Morella.

A su contenido alude el noble en el texto de la Crónica, cuando le insiste al rey: vos me faes carta que si jo prenia algun logar de moros, que fos meu... (22).

Incluidas asimismo dentro de este tipo documental de las donaciones, podemos citar las que Jaime I realizara como consecuencia de las conquistas de Mallorca y Valencia, que anotadas en un libro registro dieron lugar a los que hoy conocemos como llibres de repartiment.

De la existencia de las mismas son testimonio las siguientes citas. Respecto a la primera, al programar la conquista de Mallorca, los hombres de Barcelona pidieron al rey quels faessen carta segons quel partiment seria de les terres que nos goanyariam ab els, e dels mobles, ... (23); estas promesas se fueron luego realizando en el mencionado llibre de repartiment asimismo nombrado en el texto, e fer ho hem contar al libre com als altres ... (24).

También hallamos alusiones a las donaciones extendidas con motivo de la conquista de Valencia, las cuales resultan superiores a los bienes a repartir, lo que hace reflexionar al monarca y reducir, por una parte, la medida a emplear para la entrega de tierras; por otra, las propias donaciones cuando resulten excesivas, aumentándolas en caso contrario (25).

\section{CARTA DE CONFIRMACIÓN}

A ella se alude al menos una vez durante el sitio de Burriana, en que el monarca es presionado por los maestres de las órdenes militares que, a cam- 
bio de prestarle ayuda, le exigen la confirmación de todos sus privilegios, lo que al principio deniega el rey. Sin embargo, dicha confirmación tiene lugar al convencérsele de que puede no ser más que una ficción, la cual puede incumplir más adelante.

La petición previa a la concesión habla de que vos quens confermats aqueles cartes que havem de vostre linatge. A la confirmación, Jaime I la denomina gran carta (26).

\section{CARTA DE DESAFIO}

Está solamente mencionada y se la envía Ferriz de Lizana al rey. Desconocemos totalmente, por tanto, su tenor y demás circunstancias (27).

\section{CARTA DE CREENCIA}

Ya quedó citada anteriormente al hablar de las cartas escritas en árabe, y es la que Jaime I manda dar a los nobles que serán sus mensajeros y embajadores ante el rey de Mallorca. El propio texto la denomina asi: e faem los fer carta, en algaravia, de crehença ... (28).

\section{PACTOS O CONVENIENCIAS}

Representan el mayor número de documentos que podemos individualizar, cosa lógica ya que la narración está centrada en su mayor parte en los avances territoriales que Jaime I realizara a costa del poder de los musulmanes, y muchas de estas anexiones vienen expresadas por sus correspondientes instrumentos diplomáticos.

Por ello es el núcleo más importante de los acuerdos o pactos, el formado por aquellos que fueron consecuencia de las cartas a las que antes aludíamos, por las que los musulmanes ofertaban su rendición a cambio de una posterior posición ventajosa. Entre ellos podemos contabilizar las dirigidas a los moros de Uxó (29), Nules (30), Bairén (31), Alzira (32), Biar (33), Elche (34), e incluso a los musulmanes de Murcia (35).

Las características de todos estos acuerdos son semejantes y además de la serie de condiciones ventajosas para el rey, impuestas por él, en todas ellas se garantiza la convivencia futura de los rendidos, en similar situación a la que gozaban anteriormente, de lo que se hace eco la documentación. 
Así en la rendición de Uxó el monarca explica que faem los cartes de la lur ley que la tinguessen, e de totes lurs costumes, aixi com les solien haver en temps de sarrains; e quens donassen dretura aixi com faye al rey lur.

Otro ejemplo tenemos en el caso alcireño, en que se pone en boca de los «viejos» las siguientes palabras: $E$ faeren ses cartes ab nos com romanessen en Algezira ab aquels furs e custumes que eren temps de los almohades, e que poguessen fer lur offici en les mesquites aixi com solien....

Caso especial dentro de este subgrupo lo forma el murciano, ya que a la dación de este documento, le precede la presentación por parte de los sometidos de un memorial, a cuyos puntos deberá someterse el posterior tratado. Así lo especifica la Crónica: ... e que ells aduyen una carta aqui dels capitols que demanaven, e deyen que en aquela manera los faessem la carta. Ab tant mostraren nos un escrit de la memoria quels havien donada e aquel acort que havien empres...

De diferente carácter aun dentro de este mismo apartado, aunque no grupo, es el pacto firmado entre Jaime I y Zeit Abu Zeit, el depuesto rey de Valencia, en 1229 (36). Sobre este asunto dice el rey en la Crónica: $E$ fo nostre acort que aguessem treuga ab Seyt Abuzeit, qui era lavos rey de Valencia, $q$ quens donas la quinta de Valencia e de Murcia de les rendes que el havia, levades les peytes, e le atorgans ho ab cartes e ab covinençes que el nos feu. E faem la treuga ab el (37). La trascendencia de este acuerdo fue enorme, ya que con el mismo y con su confirmación, Zeit Abu Zeit renunció completamente a sus pretensiones sobre el reino de Valencia en favor del aragonés.

De destacar en alguno de estos documentos de carácter pactual son las cautelas aplicadas en la confección de originales múltiples que el mismo rey conquistador conoce y cita. Nos estamos refiriendo a las llamadas cartas partidas o cartas partidas por a.b.c., caracterizadas por llevar trazadas estas letras o todas las del alfabeto en el espacio que separa la redacción de los diferentes originales, y que luego sufrirá un determinado corte que garantizará, o al menos dificultará la posterior manipulación o falsificación de los mismos.

Hallamos referencia a una carta de este tipo con motivo del ataque que las tropas reales sufrieron por parte de los musulmanes, alentados por el alcalde de Játiva, algún tiempo antes de que Jaime I decidiera la conquista de esta plaza fuerte. Ante el hecho, el monarca decide llamar al alcaide a su presencia y le reprocha su conducta aduciendo que vos sabets que la covinença que havets ab nos, que les cartes partides son per a.b.c., que nos ne tenim les unes e vos ne tenits les altres; e segons que en aqueles es contengut, havets vos trencades les covinençes que haiets ab nos (38). Es quizás 
el testimonio diplomático más interesante que recoge este texto, pues explica claramente el procedimiento -el corte de las cartas y la aposición de las letras del alfabeto-, la existencia de dos cartas consecuencia de un tratado bilateral y que cada una de ellas esté en posesión de las respectivas partes.

$Y$ finalmente, dentro de este bloque de los acuerdos, podemos individualizar un último tratado, el de Almizra, suscrito entre el rey de Castilla y el de Aragón, en 1244, por el cual se delimitaba el área de reconquista correspondiente a cada uno (39).

Sobre el mismo, la crónica real es muy explícita indicando el negocio jurídico: Aquest fo lo partiment de les terres, lo que le çorresponde a cada una de las partes: que l'infant hagues... e nos que haguessem y la forma de validación: ...e faem nostres cartes bulades (40).

\section{PLEITO}

Se trata del entablado entre el conde de Ampurias y Ponce Guillem de Torrella - ya citado-, acerca de las pretensiones del primero sobre este último lugar y algunos otros aspectos, y del mismo se aprecian todas las fases a recorrer hasta llegar a la oportuna sentencia. Dice el texto: $E$ hoida aquesta demanda e lur resposta anem a Monpeyler e alongam lo pleyt tro nos venguessem, e lexam hi un escriva que preses testimonis e recuylis lo feyt. E quan nos venguessem que y donassem sentencia (41), de lo que se desprende que demanda, testimonios, recogida de información y sentencia conforman este tipo diplomático.

Sobre una de estas fases - la declaración de los testigos- tenemos información añadida en el pasaje que trata de la falsificación de moneda, donde se arbitra el procedimiento para la toma de juramento previa a la declaración.

Para ello, dice el texto, ... tenguem apparaylat un test Evangeli en que juras, e haguem ... un escriva nostre per scriure los dits que ell diria e faem lo jurar que dixes veritat e que no sen lexas per amor ni per temor ni per haver que hom lin donas... (42).

\section{TESTAMENTO}

Las últimas voluntades es uno de los testimonios diplomáticos que nunca suelen faltar en ningún relato, y así no iba a ser éste la excepción. Corres- 
ponde en la ocasión presente al ordenado por la hija de Jaime I y del mismo se menciona su denominación, los albaceas que deberán dar cumplimiento al mismo, su lectura para darlo a conocer y parte de su articulado, como puede apreciarse en la siguiente cita: $E$ puys vengueren a nos ... qui eren sos marmessors e dixeren quens volien mostrar lo seu testament, e nos hoim lo e trobam en aquell que lexava... (43).

\section{TREUDO O TRIBUTO}

Es ya el último de los documentos que individualizamos dentro de esta tipología y quizás deberíamos más que hablar de su existencia hacerlo de lo contrario, ya que en realidad no se llega a suscribir ningún documento de este cárácter ante la negativa del rey conquistador a llevarlo a efecto.

El asunto se remonta a tiempos anteriores, en que los antecesores de Jaime I fueron feudatarios de la Santa Sede, y en estos momentos, Gregorio $X$ - a cuya carta aludíamos ya anteriormente - intenta renovar esta condición y lograr la ayuda económica de Aragón para intervenir en Tierra Santa.

La respuesta por parte de Jaime I es afirmativa por lo que respecta al apoyo económico, aunque discrepa sobre la cuantía de la misma y su obligación, negándose en última instancia a suscribir nuevo documento que así lo hiciera constar. El asunto queda así narrado en la Crónica: ... e que laus daria de bon grat mas que no fermassem un trahut que nostre pare havia donat sobrel regne de Arago a Roma quan se corona en Roma, que era de CCL marmudines jusiphies ... e que puys que nos ho faessem segons que nostre pare ho havia feyt. E nos responem los en aquesta manera, quens maraveylavem molt, car ell nos demanava trahut del temps de nostre pare a ença ... pero si molt lo volia de nos quel li darien ... mas que carta no fariem de novel quens metessem en trahut... (44).

Una última consideración diplomática podríamos añadir respecto a las hasta aquí mencionadas y ésta referida a la forma de validación de las cartas mediante la aposición del sello. En uno de los ejemplos se indica la condición de selladas referidas a las cartas. Se trata de la firma del tratado de Almizra, ya citado, en que al final se especifica que han hecho nostres cartes bulades.

La otra mención es más expresiva. Se trata de la rendición de Menorca y de ella dice el rey que faem nostres cartes ab nostre sagell quels donam... (45). 
Los ejemplos todavía podrian sucederse si espigáramos más detenidamente el texto de Jaime I, sin embargo es suficiente la muestra aquí ofrecida para reconocer su valor diplomático que por otra parte estimamos muy lejos de la intencionalidad del autor. 



\section{NOTAS}

(1) Cfr. CABANES PECOURT, M.D., “La diplomática valenciana en la literatura valenciana de Tirant lo Blanch», Anales de la Academia de Cultura Valenciana, núm.63 (1986), pp. 83-105.

(2) Cfr. JAIME I, Crónica, fols. 86r-87r.

(3) Crr. JAIME I, Crónica, fol. 172v.

(4) Cfr. JAIME I, Crónica, fol. 175r.

(5) Cfr. JAIME I, Crónica, fol. 167r.

(6) Cfr. JAIME I, Crónica, fol. 62v. Dice así: E fahem los fer carta en algaravia, de creença, a un alfaqui nostre de Saragoça, per nom don Salomon, germa de don Bahiel, que creeguessen a aquests tots tres de la missatgeria.

(7) Ocasión de redactar el diploma en árabe se le plantea a Jaime I cuando ordena la expulsión de los musulmanes del Reino, después de la rebelión de Alazrach, lo que ejecuta $E$ enviam les cartes e missatges en arabich... Cfr. JAIME I, Crónica, fol. 145v.

(8) E comptans quels sarrains de Paniscola havien enviat // sarrains a don Exemen d'Orrea ... e enviaus mi aqui ab la carta quels sarrains li enviaren; e nos faem la ligir a I sarrahi que havia en Terol, qui sabia ligir d'algaravia. Cfr. JAIME I, Crónica, fol. 86r.

(9) Cfr. JAIME I, Crónica, fol. 185r.

(10) Cfr. JAIME I, Crónica, fol. 175r.

(11) Cfr. JAIME I, Crónica, fol. 150r.

(12) Cfr. JAIME I, Crónica, fol. 161v.

(13) Cfr. JAIME I, Crónica, fol. 135r.

(14) Cfr. JAIME I, Crónica, fol. 172v.

(15) Cfr. JAIME I, Crónica, fol. 144r.

(16) Cfr. JAIME I, Crónica, fol. 189v. Aquí hace alusión al carácter de ruego o plegaria que tiene la carta: ab carta ... en quens pregava...

(17) Cfr. JAIME I, Crónica, fol. 109v.: I sarrai cubertament que entra en la ost de nuyt ab una carta daquels moros ab que nos haviem parlat. E deya la carta que vinguessem a Almena. ra cant nos volriem.

(18) Cfr. JAIME I, Crónica, fol. 112r.

(19) Cfr. JAIME I, Crónica, fol. 150v.

(20) Façats una carta, faem los fer carta, faem los cartes, faem nostres cartes, son distintas formas de una misma expresión que se presenta repetidamente en la Crónica al aludir a la "conscriptio" documental. Cfr. JAIME I, Crónica, fols. 80r., 62v., 111r. y v., 128v., 140r., 142v., 149r., etc.

(21) Cfr. HUICl, A. y CABANES, M.D., Documentos de Jaime I de Aragón, I, Valencia, 1976, núm. 85.

(22) Cfr. JAIME I, Crónica, fol. 69v.

(23) Cfr. JAIME I, Crónica, fol. 32r.

(24) Cfr. JAIME I, Crónica, fol. 54v. 
(25) Cfr. JAIME I, Crónica, fol. 121r. en que dice: E quan vench a enant en torn de IIII setmanes, metem partidos que partissen la terra del terme de Valencia. E vim les cartes de la donacions que nos feytes haviem, e trobam que eren mes les cartes que no bastaria al terme segons les donacions que nos feytes haviem a alguns...

(26) Cfr. JAIME I, Crónica, fol. 80r. La confirmación puede cfr. HUICI-CABANES, Documentos de Jaime I de Aragón, I, núm. 182.

(27) Cfr. JAIME I, Crónica, fol. 172v.

(28) Cfr. JAIME I, Crónica, fol. 62v.

(29) Cfr. JAIME I, Crónica, fol. 11tr.

(30) Cfr. JAIME I, Crónica, fol. 111v.

(31) Cfr. JAIME I, Crónica, fol. 128v.

(32) Cfr. JAIME I, Crónica, fol. 133r. y v.

(33) Cfr. JAIME I, Crónica, fol. 142v.

(34) Cfr. JAIME I, Crónica, fol. 162v.

(35) Cfr. JAIME I, Crónica, fol. 168.

(36) Cfr. HUICI-CABANES, Documentos de Jaime I, I, núm. 119, que fue luego confirmado en 1236, cfr. HUICI-CABANES, Documentos de Jaime I, II, núm. 236.

(37) Cfr. JAIME I, Crónica, fol. 13v.

(38) Cfr. JAIME I, Crónica, fol. 135v.

(39) Cfr. HUICI-CABANES, Documentos de Jaime I, II, núm. 388.

(40) Cfr. JAIME I, Crónica, fol. 140r.

(41) Cfr. JAIME I, Crónica, fol. 172v.

(42) Cfr. JAIME I, Crónica, fol. 175r.

(43) Cfr. JAIME I, Crónica, fol. 176r.

(44) Cfr. JAIME I, Crónica, fol. 193v.

(45) Cfr. JAIME I, Crónica, fol. 63v. 